\title{
Saudi Journal of Engineering and Technology
}

Abbreviated Key Title: Saudi J Eng Technol ISSN 2415-6272 (Print) |ISSN 2415-6264 (Online)

Scholars Middle East Publishers, Dubai, United Arab Emirates Journal homepage: https://saudijournals.com/sjeat

Original Research Article

\section{Effect of Weight Stabilization before Curing of V-Belt}

Abdul Kalam Azad John Mohamed*

Jubail Industrial College, P.O. Box: 10099, Jubail Industrial City-31961, Kingdom of Saudi Arabia

DOI: $10.36348 /$ sjet.2020.v05i05.002

| Received: 06.04.2020 | Accepted: 24.04.2020 | Published: 07.05.2020

*Corresponding author: Abdul Kalam Azad John Mohamed

Abstract

\section{Graphical Abstract}

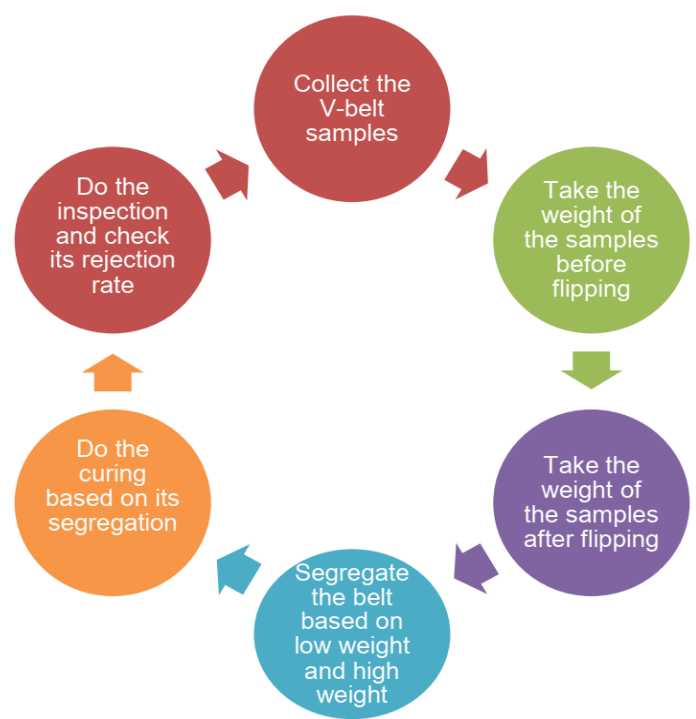

The aim of this method is to reduce the rejection rate in V-belt using weight stabilization method. Low Belt, Double Jacket, Topping Air, and Base Air are the major rejection in V-belt due to the dissimilar weight in V-belt as the weight plays a vital role in determining the quality of a product and processing parameter such as pressure and heat. The above problems can be rectified by taking weight during the final processing stage of V-belt subsequently it can be segregated depending upon the weight range before curing and then set the curing parameters. Another aspect of taking correct weight every time for the same length \& cross section of belt is the regularity of dimension. I vehemently envisage that this method can be used to reduce the rejection rate based on dissimilar weight for any rubber based products not only the $\mathrm{V}$-belt. The benefits of this method is extended below

- Sophisticated device are not required to implement this method.

- Products having uneven weight can be converted into defect free product.

- Rejection rate can be firmly controlled.

Keywords: V-belt; Weigh; Stabilization; Curing.

Copyright @ 2020: This is an open-access article distributed under the terms of the Creative Commons Attribution license which permits unrestricted use, distribution, and reproduction in any medium for non-commercial use (NonCommercial, or CC-BY-NC) provided the original author and source are credited.

\section{METHOD}

Fish bone diagram as shown in the figure 1 has been used as a preliminary tool [1] to find out the various causes for dissimilar weight in V-belt which leads to higher rejection rate by dint of insufficient quality and in order to reduce this rejection rate a new method has been established to stabilize the weight as mentioned below in the following steps.

\section{Equipment}

- Weighing machine

- Horizontal roto curing drum

- Vernier caliper 


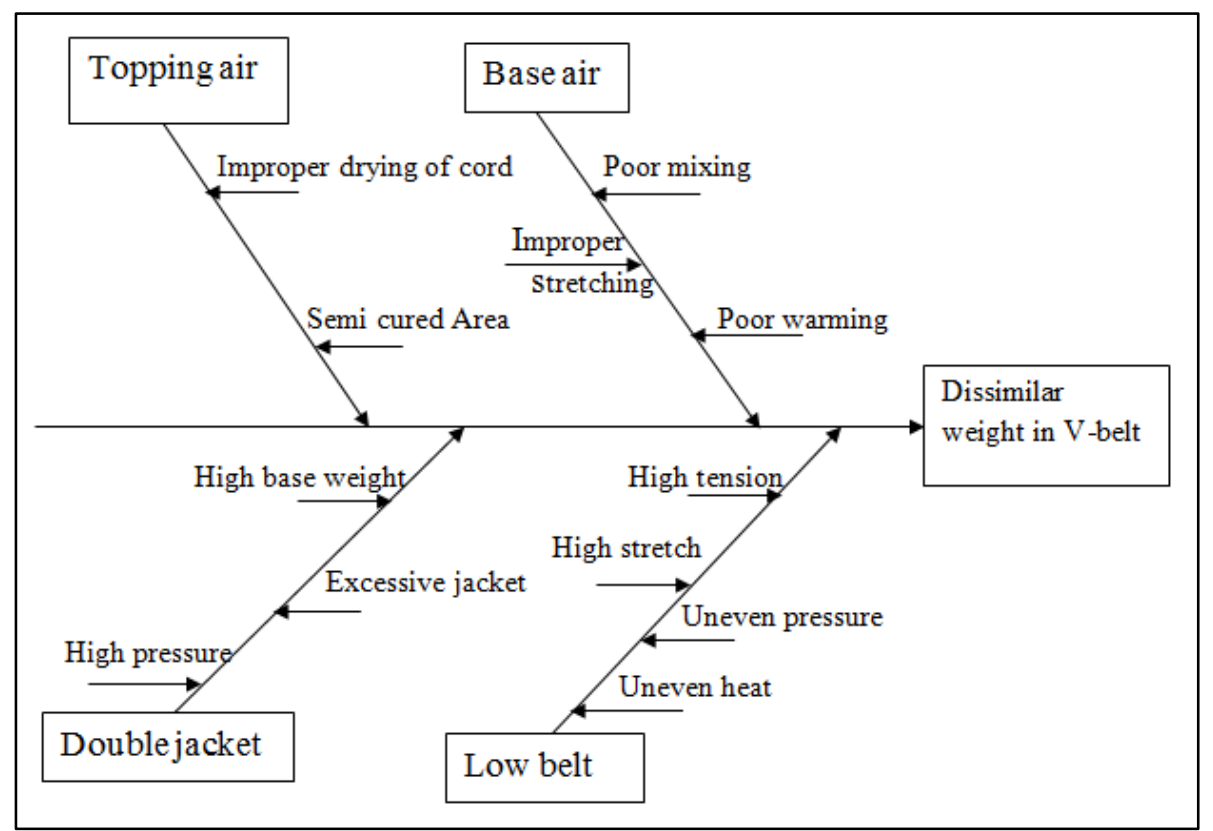

Fig-1: Fish bone diagram

\section{Record the weight of V-belt}

Take the weight of raw belt before flipping as well as after flipping as it is a process of wrapping the raw belt for further defending the internal composition of V-belt. There after take the weight after the curing process in terms of gram per inch for the cluster of Vbelt.

\section{Segregate the V-belt}

Segregate the belt for its next curing stage according to the maximum and minimum value of weight and then set the tolerance value.

\section{Curing}

Set the temperature \& pressure in a horizontal roto curing drum according to its specification and weight range as higher pressure is needed to apply for low weight belt and lower pressure for belt having more weight.

\section{Inspection}

After completion of curing and cooling process, measure the dimension of cured V-belt with the help of Vernier caliper and inspect the quality of $\mathrm{V}$ belt to separate the defect products.

When over viewing and going through the various studies conducted, it has been observed that the rejection rate was reduced from $0.6 \%$ to $0.3 \%$ by avoiding Base Air, Topping Air, Double Jacket, and nearly zero rejection in Low belt through this weight stabilization method together with the production feasibility as shown in the figure 2 .

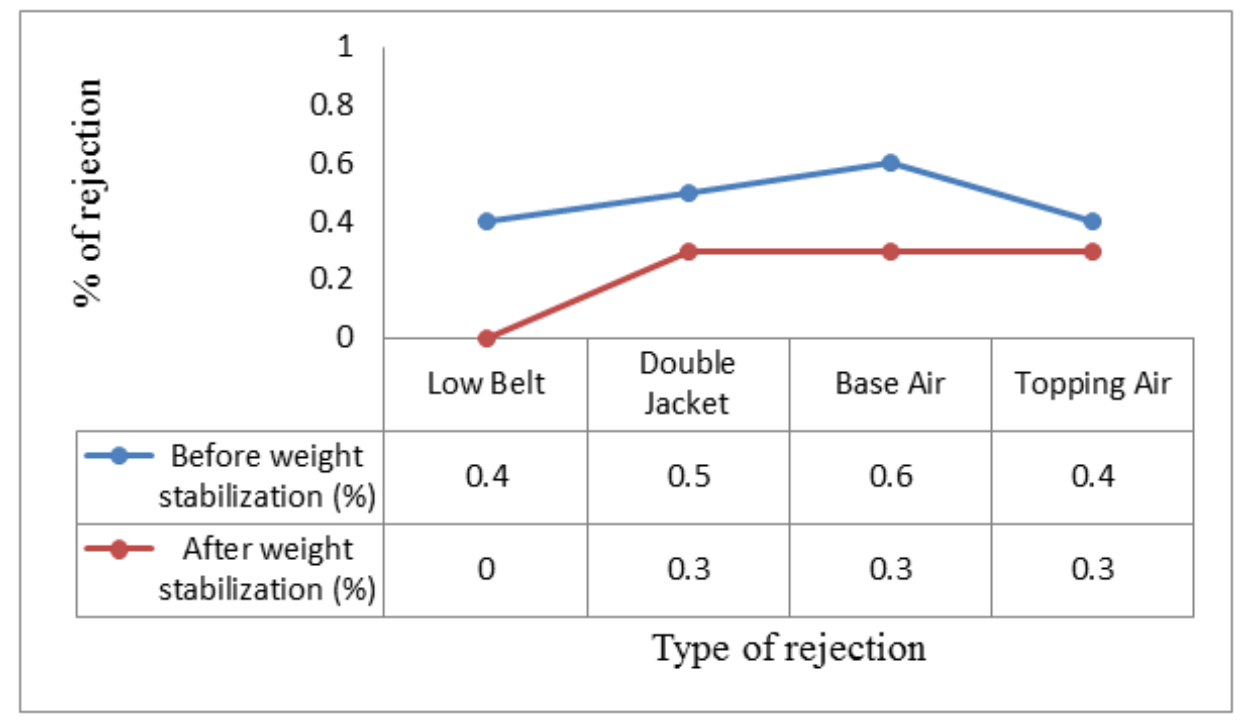

Fig-2: Comparison of rejection rate before and after stabilizing the weight 


\section{Method Validation}

In order to validate this method, 15 batches of $\mathrm{V}$-belt have been taken into an account as presented below.

\section{Batch-1:}

Segregation of belt : +30 gram $\&-30$ gram

Pressure between drum $\&$ wire pad

For $+30: 700$ psi

For $-30: 730$ psi

Drum rotation : $660 \mathrm{rpm}$

\begin{tabular}{|l|l|l|l|l|}
\hline Dimension & Average & Maximum & Minimum & Range \\
\hline Before flipping (g) & 5.565 & 5.681 & 5.451 & 0.231 \\
\hline After flipping (g) & 7.391 & 7.505 & 7.253 & 0.253 \\
\hline After curing (g) & 334.0 & 0.36 & 0.304 & 0.056 \\
\hline
\end{tabular}

\section{Result:}

Total : 17

Ok : 17

Rejection : nil

Reason : proper pressure has been given to this batch according to the weight.
Batch-2:

Segregation of belt : +70 gram $\&-70$ gram

Pressure between drum \& wire pad

For $+70: 700 \mathrm{psi}$

For $-70: 740 \mathrm{psi}$

Drum rotation : $660 \mathrm{rpm}$

\begin{tabular}{|l|l|l|l|l|}
\hline Dimension & Average & Maximum & Minimum & Range \\
\hline Before flipping (g) & 6.159 & 6.363 & 5.887 & 0.476 \\
\hline After flipping(g) & 7.922 & 8.218 & 7.613 & 0.605 \\
\hline After curing (g) & 433.75 & 546 & 318 & 228 \\
\hline
\end{tabular}

Result:

Total : 17

Ok : 17

Rejection : nil

Reason : proper pressure has been given to this batch according to the weight.
Batch-3:

Segregation of belt : +40 gram $\&-40$ gram

Pressure between drum $\&$ wire pad

For $+40: 560 \mathrm{psi}$

For $-40: 590 \mathrm{psi}$

Drum rotation : $540 \mathrm{rpm}$

\begin{tabular}{|l|l|l|l|l|}
\hline Dimension & Average & Maximum & Minimum & Range \\
\hline Before flipping (g) & 12.329 & 12.486 & 12.125 & 0.361 \\
\hline After flipping(g) & 15.51 & 15.764 & 15.208 & 0.556 \\
\hline After curing (g) & 408.154 & 482 & 230 & 252 \\
\hline
\end{tabular}

\section{Result:}

Total : 10

Ok : 10

Rejection : nil

Reason : proper pressure has been given to this batch according to the weight.
Batch-4:

There is no need to segregate the belt, since all the belts are within the range of 40 gram.

Pressure between drum \& wire pad : 730 psi

Drum rotation : $660 \mathrm{rpm}$

\begin{tabular}{|l|l|l|l|l|}
\hline Dimension & Average & Maximum & Minimum & Range \\
\hline Before flipping (g) & 3.367 & 3.461 & 3.199 & 0.262 \\
\hline After flipping(g) & 4.508 & 4.615 & 4.411 & 0.204 \\
\hline After curing (g) & 235.765 & 272 & 214 & 58 \\
\hline
\end{tabular}

\section{Result:}

Total : 23

Ok : 23

Rejection : nil

Reason : All the belts are within the range of 40gram.

\section{Batch-5:}

There is no need to segregate the belt, since all the belts are within the range of 40 gram.

Pressure between drum \& wire pad : 570 psi

Drum rotation : $450 \mathrm{rpm}$ 


\begin{tabular}{|l|l|l|l|l|}
\hline Dimension & Average & Maximum & Minimum & Range \\
\hline Before flipping (g) & 32.469 & 33.027 & 31.912 & 1.115 \\
\hline After flipping(g) & 38.543 & 38.959 & 37.91 & 1.048 \\
\hline After curing (g) & 544.714 & 584 & 472 & 112 \\
\hline
\end{tabular}

Result:

Total : 14

Ok : 14

Rejection : nil

Reason : All the belts are within the range of 40gram.
Batch-6:

Segregation of belt : +50 gram $\&-50$ gram

Pressure between drum \& wire pad

For $+50: 550 \mathrm{psi}$

For $-50: 600 \mathrm{psi}$

Drum rotation : $600 \mathrm{rpm}$

\begin{tabular}{|l|l|l|l|l|}
\hline Dimension & Average & Maximum & Minimum & Range \\
\hline Before flipping (g) & 7.186 & 7.387 & 6.864 & 0.523 \\
\hline After flipping(g) & 9.195 & 9.405 & 9.013 & 0.392 \\
\hline After curing (g) & 491.765 & 542 & 420 & 122 \\
\hline
\end{tabular}

Result:

Total : 17

Ok : 16

Rejection : (1) Jacket opening

Reason : Improper Flipping
Batch-7:

Segregation of belt : +70 gram $\&-70$ gram

Pressure between drum $\&$ wire pad

For +70

: 560

For -70

: 600

Drum rotation : $450 \mathrm{rpm}$

\begin{tabular}{|l|l|l|l|l|}
\hline Dimension & Average & Maximum & Minimum & Range \\
\hline Before flipping (g) & 31.826 & 32.627 & 31.03 & 1.597 \\
\hline After flipping(g) & 38.14 & 38.825 & 37.354 & 1.471 \\
\hline After curing (g) & 601.143 & 678 & 522 & 156 \\
\hline
\end{tabular}

\section{Result:}

Total : 14

Ok : 14

Rejection : nil

Reason : proper pressure has been given to this batch according to the weight.

\section{Batch-8:}

Segregation of belt : +60 gram \& -60 gram

Pressure between drum \& wire pad

For $+60: 550 \mathrm{psi}$

For $-60: 590$ psi

Drum rotation : $450 \mathrm{rpm}$

\begin{tabular}{|l|l|l|l|l|}
\hline Dimension & Average & Maximum & Minimum & Range \\
\hline Before flipping (g) & 30.897 & 31.43 & 29.518 & 1.912 \\
\hline After flipping(g) & 37.016 & 37.459 & 36.157 & 1.303 \\
\hline After curing (g) & 582.571 & 696 & 450 & 246 \\
\hline
\end{tabular}

\section{Result:}

Total : 14

Ok : 13

Rejection : (1) Base air

Reason : Due to Improper Warming in the two roll mill.

\section{Batch-9:}

There is no need to segregate the belt, since all the belts are within the range of $30 \mathrm{~g}$.

Pressure between drum \& wire pad : 725 psi

Drum rotation : $660 \mathrm{rpm}$

\begin{tabular}{|l|l|l|l|l|}
\hline Dimension & Average & Maximum & Minimum & Range \\
\hline Before flipping (g) & 5.766 & 5.831 & 5.685 & 0.146 \\
\hline After flipping(g) & 7.626 & 7.708 & 7.528 & 0.18 \\
\hline After curing (g) & 331.125 & 352 & 316 & 36 \\
\hline
\end{tabular}




\section{Result:}

Total : 17

Ok : 17

Rejection : nil

Reason : All the belts are within the range of 30gram.

\section{Batch-10:}

Segregation of belt : +55 gram \& -55 gram

Pressure between drum $\&$ wire pad

For +55

For -55

$: 550 \mathrm{psi}$

: $580 \mathrm{psi}$

Drum rotation : $600 \mathrm{rpm}$

\begin{tabular}{|l|l|l|l|l|}
\hline Dimension & Average & Maximum & Minimum & Range \\
\hline Before flipping (g) & 6.96 & 7.077 & 6.746 & 0.331 \\
\hline After flipping(g) & 8.778 & 8.999 & 8.441 & 0.558 \\
\hline After curing (g) & 351.882 & 408 & 290 & 118 \\
\hline
\end{tabular}

\section{Result:}

Total : 17

Ok : 16

Rejection : (1) Flipping mistake

Reason : Improper Flipping
Batch-11:

There is no need to segregate the belt, since all the belts are within the range of 30 gram.

Pressure between drum \& wire pad: 720 psi

Drum rotation : $660 \mathrm{rpm}$

\begin{tabular}{|l|l|l|l|l|}
\hline Dimension & Average & Maximum & Minimum & Range \\
\hline Before flipping (g) & 5.754 & 5.824 & 5.59 & 0.234 \\
\hline After flipping(g) & 7.379 & 7.454 & 7.268 & 0.185 \\
\hline After curing (g) & 333.125 & 364 & 298 & 66 \\
\hline
\end{tabular}

\section{Result:}

Total : 17

Ok : 16

Rejection : (1) Band touch

Reason : Teared Fibre cloth is used during the curing period.

\section{Batch-12}

There is no need to segregate the belt, since all the belts are within the range of 40 gram.

Pressure between drum \& wire pad : 720 psi

Drum rotation : $660 \mathrm{rpm}$

\begin{tabular}{|l|l|l|l|l|}
\hline Dimension & Average & Maximum & Minimum & Range \\
\hline Before flipping (g) & 5.734 & 5.845 & 5.555 & 0.291 \\
\hline After flipping(g) & 5.949 & 6.045 & 5.864 & 0.182 \\
\hline After curing $(\mathrm{g})$ & 48.133 & 80 & 18 & 62 \\
\hline
\end{tabular}

\section{Result:}

Total : 16

Ok : 15

Rejection : (1) Band touch

Reason : Teared Fibre cloth is used during the curing period.

\section{Batch-13}

There is no need to segregate the belt, since all the belts are within the range of 30 gram.

Pressure between drum \& wire pad : 720 psi

Drum rotation : $660 \mathrm{rpm}$

\begin{tabular}{|l|l|l|l|l|}
\hline Dimension & Average & Maximum & Minimum & Range \\
\hline Before flipping (g) & 5.357 & 5.52 & 5.076 & 0.444 \\
\hline After flipping(g) & 7.525 & 7.591 & 7.467 & 0.124 \\
\hline After curing (g) & 487.882 & 542 & 460 & 82 \\
\hline
\end{tabular}

\section{Result:}

Total : 17

Ok : 17

Rejection : nil

Reason : All the belts are within the range of 30gram \& proper pressure is given.
Batch-14:

Segregation of belt : +75 gram $\&-75$ gram

Pressure between drum $\&$ wire pad

For $+75: 700 \mathrm{psi}$

For $-75: 740 \mathrm{psi}$

Drum rotation : $600 \mathrm{rpm}$ 


\begin{tabular}{|l|l|l|l|l|}
\hline Dimension & Average & Maximum & Minimum & Range \\
\hline Before flipping (g) & 7.051 & 7.335 & 6.733 & 0.603 \\
\hline After flipping(g) & 8.961 & 9.178 & 8.644 & 0.534 \\
\hline After curing (g) & 557.765 & 622 & 424 & 198 \\
\hline
\end{tabular}

\section{Result:}

Total : 17

Ok : 16

Rejection : (1) Double Jacket

Reason : High Pressure
Batch-15:

Segregation of belt : +60 gram \& -60 gram

Pressure between drum \& wire pad

For $+60: 720 \mathrm{psi}$

For $-60: 750 \mathrm{psi}$

Drum rotation : $540 \mathrm{rpm}$

\begin{tabular}{|l|l|l|l|l|}
\hline Dimension & Average & Maximum & Minimum & Range \\
\hline Before flipping (g) & 12.814 & 12.995 & 12.462 & 0.533 \\
\hline After flipping(g) & 15.473 & 15.703 & 15.077 & 0.626 \\
\hline After curing (g) & 476.214 & 622 & 308 & 314 \\
\hline
\end{tabular}

\section{Result:}

Total : 11

Ok : 11

Rejection : nil

Reason : proper pressure is given to this batch according to the weight.

\section{ACKNOWLEDGEMENTS}

The author would like to thank everyone who have supported during this research work.

\section{REFERENCES}

1. Praveen, P. J., \& Senthil, A. B. (2005). Total Quality Management, Scitech publications (India) PVT. LTD. 